\title{
Research on Linguistic Landscape from the Perspective of City Tourism Image Shaping: A Case Study of Anchang Ancient Town
}

\author{
Yuning Zhang, Yanfei Shen \\ Zhejiang Yuexiu University, Shaoxing, China \\ Email: 2994870959@qq.com
}

How to cite this paper: Zhang, Y.N. and Shen, Y.F. (2022) Research on Linguistic Landscape from the Perspective of City Tourism Image Shaping: A Case Study of Anchang Ancient Town. Open Access Library Journal, 9: e8386.

https://doi.org/10.4236/oalib.1108386

Received: January 20, 2022

Accepted: February 8, 2022

Published: February 11, 2022

Copyright $\odot 2022$ by author(s) and Open Access Library Inc.

This work is licensed under the Creative Commons Attribution International License (CC BY 4.0).

http://creativecommons.org/licenses/by/4.0/

\begin{abstract}
With the rapid development of modern society and economy, our country is committed to the construction of the developed country, and the tourism industry, as the tertiary sector of the economy, is restricted by the economic development. In order to promote the development of tourism and create a good tourism image of ancient towns in cities, this paper analyzes the influence of language landscape on the image of urban tourism, taking the ancient town of Anchang in Shaoxing as an example to investigate, by observing various language signs in Anchang ancient town, this paper probes into the features of the language landscape of Ancient Town, and discusses the problems existing in the language landscape of ancient town.
\end{abstract}

\section{Subject Areas}

Tourism Economy

\section{Keywords}

Linguistic Landscape, City Tourism Image, Ancient Town Scenic Spot

\section{1. 引言}

众所周知, 我国的经济得以快速发展的关键是走工业化道路, 为了 GDP 得以持续增长, 自改革开放以来, 我国将重心放在建设工业化国家上, 为了 实现供给侧的改革, 第三产业的发展受到一定影响。根据中国旅游研究院发 布的《2021 年旅游经济运行分析与 2022 年发展预测》(中国旅游经济蓝皮书 No.14), 受宏观经济和疫情的叠加影响, 2021 年第三季度, 国内旅游总人次 同比下降 $18.3 \%$, 消费面和产业面信心减弱; 综合考虑宏观经济疫情影响和 市场因素，预计 2022 年国内旅游人数 39.80 亿人次，国内旅游收入 3.81 万亿 
元, 同比分别增长 16\%和 27\%, 恢复至 2019 年同期水平, 七成预计入境旅游 人数同比增长达两成, 恢复至 2019 年的 2 到 3 成 [1]。由此可见, 旅游业发展 在一段时间内处于低迷状态。在此阶段, 我国仍应坚持旅游供给的产品创新 和相关项目研发，建设城市旅游形象，保证都市休闲、乡村度假等文化消费 需求, 以待疫情缓和之时, 迎来旅游服务业的春暖花开。

语言文字作为城市历史的重要组成元素, 也是体现现代特色的标志, 它 在过去与今时之间架起了桥梁。要想推动城市旅游发展, 必先梳妆其门面。 因此, 语言景观建设与城市旅游建设休戚与共。在经受视觉洗礼后, 城市旅 游形象必将散发其魅力。

\section{2. 文献综述}

\section{1. 语言景观}

语言景观是城市文化风韵的更为直观的体现, 而城市语言景观的建设是 衡量一个城市关于城市旅游文化业内外综合能力的重要指标之一。对于 “语 言景观” , 可以做出如下定义: 语言景观是呈现在大众视野面前的一种文字 符号, 例如路名、街名、城市名、广告牌、公共指示语、标语口号、店铺招 商牌等。在 21 世纪, 语言景观的宣传方式层出不穷。城市的语言景观除了实 体语言景观外, 还涵盖了门户网站、语音指引、网络宣传等各方面, 如图 1 。 语言景观随时间的推移而不断完善, 据前期观察分析可知, 实体语言景观已 得到了较大的提升, 而虚拟的语言景观即通过网络媒体信息技术手段传播的 语言景观关注度依旧远远落后。

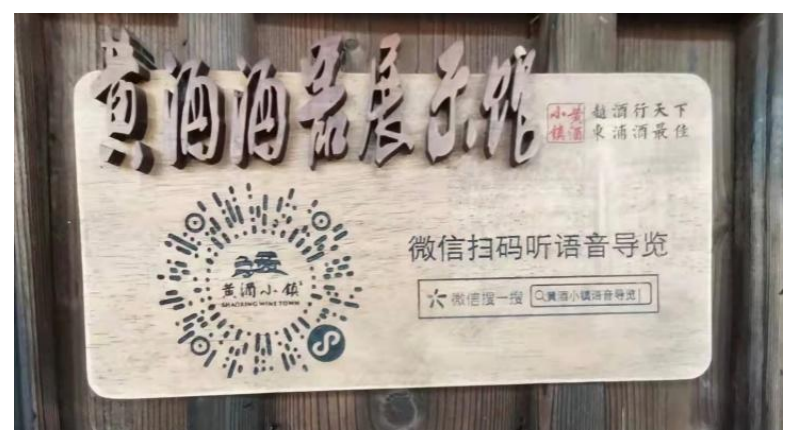

图 1. 虚拟语言景观展示图

\section{2. 国内外研究}

国外对语言景观的研究大致经历了三个阶段: 1997 年前的早期萌芽阶段, 1997-2007 年的中期理论探索阶段, 以及 2008 年之后的近期快速发展阶段。 三个研究阶段分别经历了 1997 年语言景观概念的界定、语言景观两大功能的 正式提出、其研究理论分析框架逐渐形成, 如关注度极高的场所符号学理论, 以及学科研究进一步显性化[2]。语言景观学研究的范畴已从专注标牌语言用 法研究延伸到对语言文字 “表象” 背后的身份认同、语言政策、社会机制、 意识形态等深层问题的研究。

相比之下, 国内对语言景观研究起步较晚, 关注度也相对较低。直至 2014 
年, 相关研究才有了较为稳定的发展, 出现了对语言景观研究视角、理论构 建、研究方法等的引介[3]。然而国内起步虽晚, 但近年来历久弥新, 实证研 究方面不断取得进步, 研究理论方法的文献也开始增多, 它们既包括基础研 究框架的介绍, 也包括理论与实例相结合的研究, 共 29 篇, 约占总文献数的 $27.62 \%$ 。11.43\%的文献为国内外语言景观研究综述 [4]。

通过在中国知网上对 “城市旅游语言景观” 这几个关键词的搜索, 发现 鲜有学者对此进行深刻探究。柴畅的城市国际化背景下特色商业街区语言景 观研究围绕杭州这个城市展开, 选取杭州最具特色的 5 条商业街区, 从语码 分布、官方标牌和私人标牌、语码取向等来解读语言景观的话语建构模式, 探寻双语或多语景观的译写问题 [5]。这固然对城市语言景观的译写问题进行 了系统的说明, 但是缺乏对城市古镇旅游业的语言景观普遍存在的问题缺少 总体梳理以及对古镇商业街的虚拟语言景观缺乏研究。此外, 张青、祁正妍 以中小城市旅游景区的语言景观建设为研究对象, 发现中小城市中普遍存在 部分语言标牌上的译文存在信息缺失、拼写错误、语法错误、中式英语等问 题, 于是提出了规范语言、美化标牌、优化译文等建议 [6]。但是此研究也未 对语言标牌上的虚拟语言景观给予充分关注, 仅仅对如何改善实体语言景观 提出了建议。本文结合城市旅游业形象的塑造与古镇文化视角下的语言景观 来深入探究语言景观发展中的不足与缺陷。

\section{3. 实证研究}

\section{1. 研究地点}

开展实证研究地点是绍兴市的安昌古镇。安昌古镇位于绍兴市柯桥区境 内西北端, 建于北宋时期, 占地面积 24 平方千米, 它与杭州市萧山区相接, 南靠柯桥城区, 北邻杭甬高速公路。同时它具有典型的江南古镇典型的建筑 特色, 一衣带水, 古朴典雅, 其特产安昌腊肠、扯白糖远近闻名, 具有水乡 风情的水上婚礼也是别具特色, 已被评为国家 $4 \mathrm{~A}$ 级景区。

一方面, 安昌古镇作为绍兴市最具代表性的古镇, 历史悠久, 其建设程 度相较于其他古镇略显优势, 占地面积以及路标、牌号总计数量较多, 易于 观察。另一方面, 安昌古镇具有历时性, 影响深远, 为广大游客所熟知。因 此它作为绍兴市古镇旅游的打卡首选的热门景点, 最具有研究的价值。

\section{2. 数据收集与分析}

主要拍摄的内容是路标、牌号、商店店牌、指路线索图等。Gorter 指出, 通过拍照来采集语言景观的数据已经成为语言景观研究的一种重要的数据采 集形式[7]。因此本研究主要采用手机相机来搜集语言景观的相关数据, 观察 景区的标识并对其进行拍摄。再对收集到的照片进行整理, 将出现问题的照 片实证和特色语言景观照片归类成两个素材包, 便于后期开展分析时使用。

\section{4. 安昌古镇语言景观的特点}

安昌古镇的语言景观近年来已经进入了一种不断奋进的状态, 其古镇内 部现存在一些其他古镇难以企及的优点, 形势逐渐向好。 
1) 字体极具多样性

商业街上的牌匾, 路标以及导线图等所采用的字体各式各样, 极具丰富 性。另外, 雕刻在石碑上的字体也加深了地域特色与文字的融合, 使得小镇 的语言景观更加具有生命力。如图 2, 石碑上的字体向我们展示了绍兴黄酒 文化中“酒”字的演变历程。

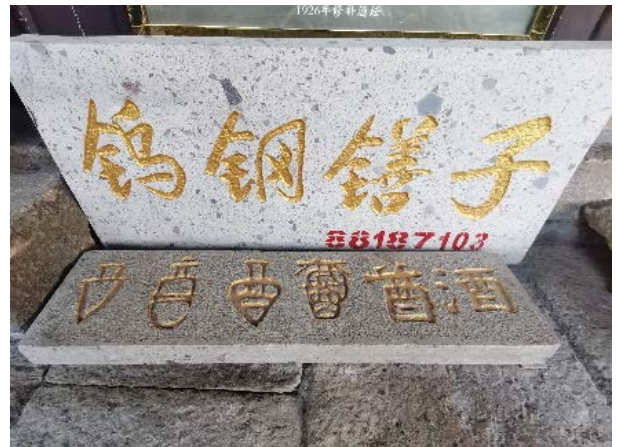

图 2. 绍兴黄酒介绍石碑

2) 宣传手法独特

结合当地的文化特色，将文字雕刻在石板、木头之上呈现给游客，如图 3。景区里存在的另一种文化是当地居民结合绍兴的酱文化，把宣传的文字印 在墙上, 在酱桶上贴上当地特色产品的文字使游客更能感受到文化气息, 如 图 4。景区介绍也采用了信息网络平台的宣传渠道, 介绍牌上还附上了音频 介绍，增强了视听效果。

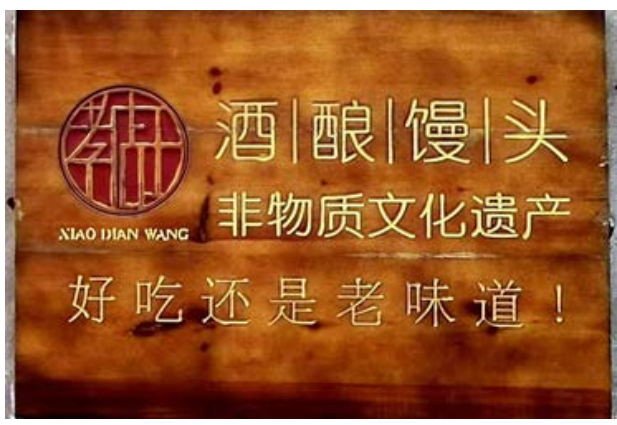

图 3. 酒酿馒头介绍牌

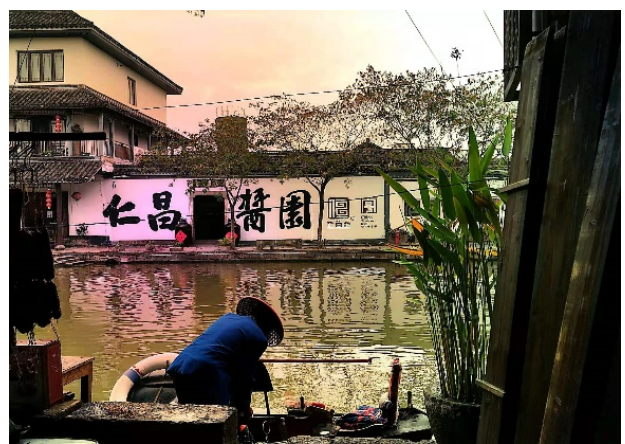

图 4. 酱园围墙 
3) 文化与商业结合

安昌古镇文化街区中的商铺招牌颇有特色。商铺招牌既是店名, 更是广 告, 招牌形象是店家实力和水平的外在表现, 顾客会产生心理信任感, 激发 购买力。因此融合语言景观在商店品牌中确实能够产生经济价值 [8]。因此, 在景区的商店店铺招牌上可见店家在命名店铺时的简单直观，直接向游客展 示了本地的特色产品, 既提高了特产的销路, 还达到了文化宣传的效果, 如 图 5。

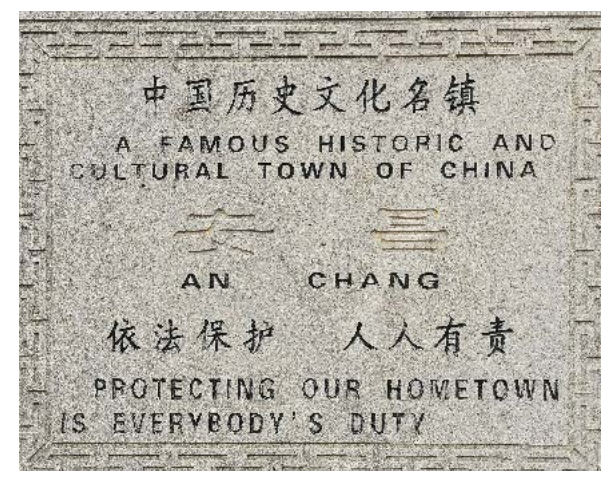

图 5. 安昌古镇石碑

\section{5. 安昌古镇语言景观的存在问题}

由上述安昌古镇具备的特点来观察, 景区的语言景观正在进步和发展, 然而从整体来分析, 古镇的语言景观依旧存在许多不足之处。

1) 使用的语种数量较少

不少路标牌仅仅采用了一种及两种的语言, 如图 6, 只有极少数的导向 牌采用了三种及以上语种, 如图 7。这种现象对语言形象发展较为不利, 例 如, 会给边陲国家的旅客造成困扰, 这就会形成文化的嫌隙, 无法体现古镇 语言景观的国际包容性和丰富性, 造成语言景观发展的不均衡。城市古镇虽 然是以中文作为主要语言书写在路标牌匾上的, 但是文化形象的树立如能摒 弃单一性, 汇入国际其他语言, 则能与世界展开交流, 架起国际沟通的桥梁。 补充多语种标牌是亟待解决的重要任务。

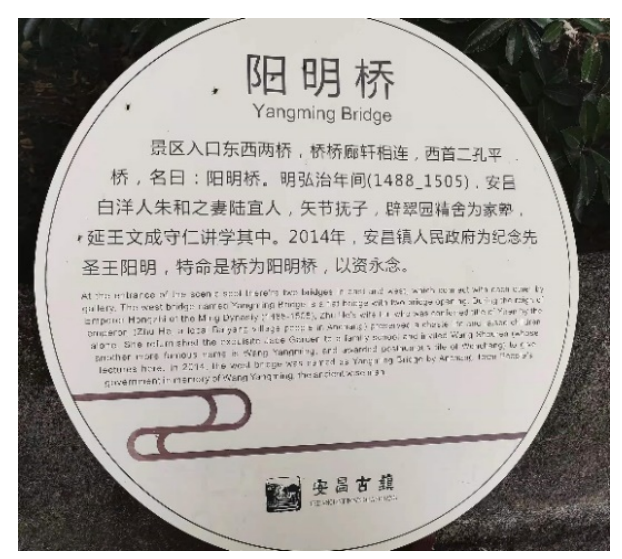

图 6. 阳明桥路牌 


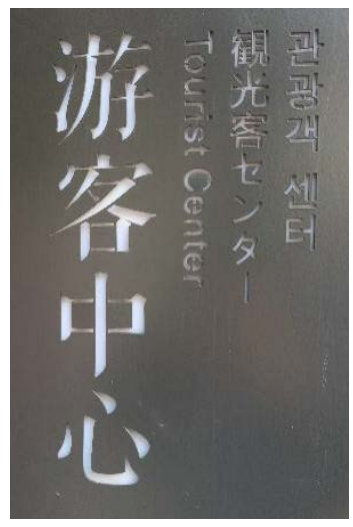

图 7. 游客中心指示牌

2) 字迹清晰度不高

不少景点的指示牌出现了模糊老旧的情况, 缺乏修缮, 如图 8。这种模 糊的字迹使得游客难以辨认, 左右为难。这对于城市古镇旅游业的形象建设 不利。在现代化进程中, 这种情况应该引起相关部门的重视, 路标路牌的翻 新情况亟需加以改善。

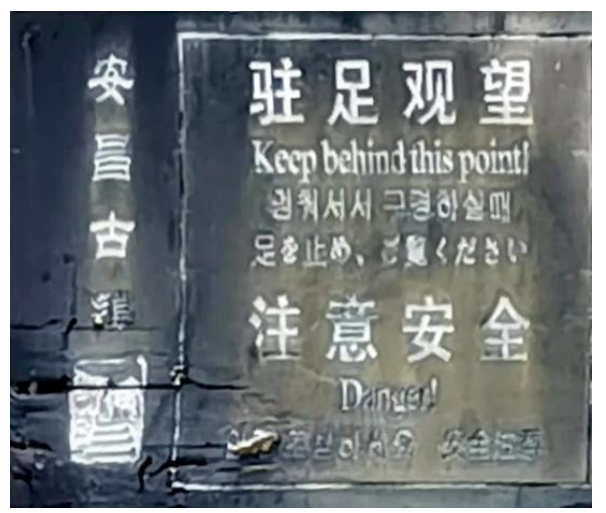

图 8. 安昌古桥路牌

3) 虚拟语言景观开发程度较低

现代城市的语言景观包括公共空间呈现的语言模态和非语言模态，既包 括文本形式，也包括图像、声音、视频等能够传达信息的复合话语。文字、 声音和图片等多模态相结合所呈现的语言景观是当前较为普遍的信息表达方 式[9]。随着社会的发展, 网络空间已成为现实生活不可或缺的一部分, 给大 众获取信息提供更为便捷的多样化途径。通过网络呈现的多模态虚拟语言景 观 [10], 与传统实体语言景观相互交融, 可为塑造现代化城市增添丰富的色彩。

安昌古镇的实体语言景观尽管存在缺陷, 但是相较与前些年已经有了极 大的改善。然而, 安昌古镇虚拟语言景观的开发还处于起步状态, 总体效果 有待提升。例如大部分特色景区的景点介绍都采用书面的文字介绍，少有可 以扫码的虚拟语言景观, 由此可见, 网络平台对于语言景观的建设还在起步 阶段, 未能建立系统的景区虚拟语言景观。此外, 不少扫码听讲解的标识遭 到了破坏。从调查来看, 二维码老旧、受损较严重, 更像是历时很久、缺乏 
人工维护更新造成的, 类似的问题同样也存在于绍兴黄酒小镇, 如图 9。在 调查过程中, 遇到了如有关内容讲解的部分无法使用微信二维码打开公众号 查看的情况。其次, 在扫码听讲解的二维码上鲜有外文介绍, 因此标牌的信 息功能难以得到充分发挥。而体现在宣传册、各景点的多语标识更为详实, 充分体现了标牌的信息价值所在，在一定程度上做到了保护与开发的平衡发 展。这种实体与虚拟语言景观的差距, 现在还处在弥合阶段。

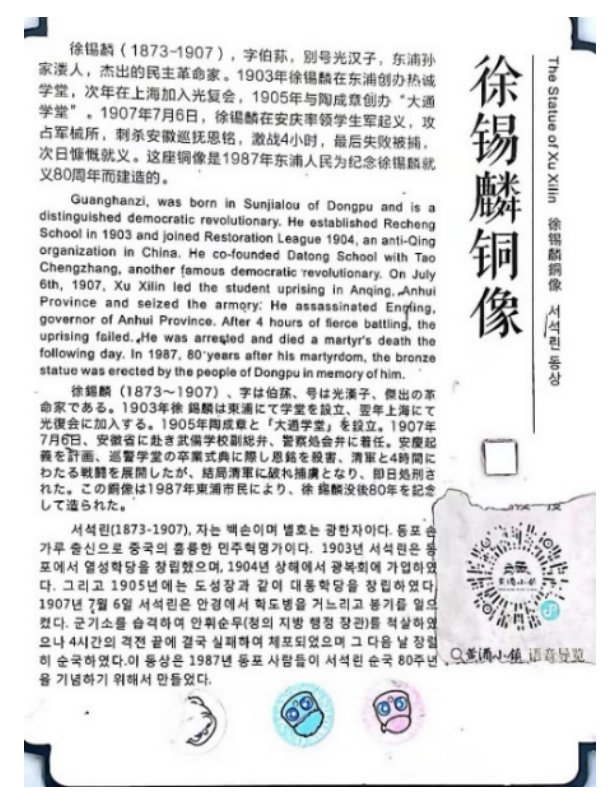

图 9. 徐锡麟铜像介绍牌

\section{6. 提升路径与建议}

经过实地考察, 安昌古镇主要存在使用语种数量较少、字迹清晰度不高、 虚拟语言景观开发程度较低等问题。针对以上问题，提出以下一些可能的提 升路径与建议, 以期对症下药, 因地制宜, 以进一步提升古镇旅游形象。

1) 改善古镇语言景观的多样性

要在符合历史文化传统为第一要义的前提下, 结合地域特色, 注重历史 文化街区语言景观建设的整体设计与规划。在语言的使用上, 采用多语种并 行的方式, 至少应包含中文, 英文, 韩文, 日文等四种基础语言, 彰显现代 化古镇文化视角下语言景观的特色。学会利用国际化的城市形象来吸引外来 游客参观, 从而促进城市古镇旅游业的发展, 展现文化魅力。

2) 美化路牌标识的面貌

及时对旧路牌进行修缮, 保证路牌标识的清晰度, 在此基础上对路标牌 号进行美化。例如在字体颜色倾向于金色黑底，在书写顺序上沿袭历史采用 坚写左行, 在书写字体上使用易于辨认又不失特色的管书、隶书、楷体等形 式。尽量使用符合传统匾额的语言标牌形式, 避免了语言标牌的过度商业化。

3) 将实体语言景观和虚拟语言景观的融合

首先, 改善实体语言景观中存在的风格杂乱的问题，采用多种字体固然 绚丽夺目, 但是风格散乱会破环景区整体的形象。因此推崇使用具有统一风 
格的几种字体, 尽量避免大量使用甲骨文等。做到与现代化进程接轨。其次, 利用微博号、微信号等电子平台进行宣传。景区内的二维码多被破坏, 因此 要解决翻新宣传平台, 清除破旧的指示标码。并在该区块的语言景观上借助 现代科技力量提升实体标牌的信息化功能。

\section{7. 结语}

国内外关于城市形象构建的相关研究主要从城市规划、建筑景观设计、 城市品牌创设等视角出发探究城市形象的提升策略, 而本研究从语言景观中 的文化视角以及结合了旅游业的发展来开展城市形象构建研究, 具有一定的 创新性。本文通过观察城市古镇中的语言景观, 包括虚拟语言景观, 总结得 出绍兴市安昌古镇语言景观存在的问题及提升措施。以安昌古镇为例提出的 提升措施在一定程度上也适用于其他城市古镇建设存在的问题, 比如语言使 用的规范性，因此具有借鉴意义。本文调查研究中获取的实证数据可以为当 地语言政策制定者提供参考，得出的论证结果为城市建设规划、文化传承提 供新的思路与借鉴。而针对安昌古镇虚拟语言景观的建设问题，网络平台优 化这一措施具有一定的技术要求，具有一定挑战性，应引起相关部门人员的 重视, 以调动力量开展建设与完善。

\section{基金项目}

2021 年国家级大学生创新创业训练计划项目 “文化传承视角下江南古镇 语言景观调查及优化策略研究” (项目编号：202112792014); 绍兴市哲学社会 科学研究 “十四五” 规划 2021 年度重点课题 “语言景观学视域下城市形象构 建中的文化传承研究” (项目编号：145060)。

\section{Conflicts of Interest}

The authors declare no conflicts of interest.

\section{References}

[1] 戴斌. 2021 年旅游经济运行分析与 2022 年发展预测 [M]. 北京: 中国旅游出版社, 2022.

[2] 梁晶晶. 语言景观在旅游汉语教学中的应用研究 [D]: [硕士学位论文]. 桂林: 广 西师范大学, 2021.

[3] 尚国文, 赵守辉. 语言景观的分析维度与理论构建 [J]. 外国语, 2014, 37(6): 81-89.

[4] 吴剑锋, 章近勇. 国内语言景观研究现状、热点及趋势——基于数据量表和知识 图谱的分析[J]. 宁波大学学报(人文科学版), 2019, 32(6): 50-56.

[5] 柴畅. 城市国际化背景下特色商业街区语言景观研究: 以杭州为例[J]. 宁波开放 大学学报, 2021, 19(4): 69-75.

[6] 张青, 祁正妍. 中小城市旅游景区语言景观调查研究一一以张掖市为例 [J]. 海外 英语, 2021(11): 101-102.

[7] Gorter, D. (2006) Linguistic Landscape: A New Approach to Multilingualism. Multilingual Matters, Clevedon. https://doi.org/10.21832/9781853599170

[8] 金杉. 江南古镇旅游标志形象感知与设计研究 [D]: [硕士学位论文]. 上海: 华东 
理工大学, 2019.

[9] 王巧, 刘美兰. 国际化城市多模态语言景观与城市形象建设一一以义乌市宾王商 贸区和稠州北路为例 [J]. 美与时代(城市版), 2021(11): 100-101.

[10] 王春梅. 高校网站的虚拟语言景观研究[D]: [硕士学位论文]. 烟台: 鲁东大学, 2020 .

\section{Appendix (Abstract and Keywords in Chinese) 城市旅游形象塑造视角下的语言景观调查研究——以安昌古镇为例}

摘要：在社会经济飞速发展的时代背景下，我国致力于建设工业化国家，旅 游业作为第三产业, 受到了经济发展的制约。为了助力旅游业的发展, 达到 塑造良好城市古镇旅游形象的目的, 本文从语言景观对城市旅游形象塑造的 影响着手剖析, 以绍兴市安昌古镇为例展开调查, 通过观察安昌古镇景区的 各类语言标牌，探究城市古镇语言景观的特点，并对古镇语言景观存在的问 题展开深入讨论, 最后提出解决路径与建议。

关键词：语言景观，城市旅游形象，古镇景区 